\title{
A Case-Control Study of Obstetric Fistula Risk Factors in the Democratic Republic of the Congo
}

\author{
Leon Mubikayi1,2,3*, Eric J. Chow ${ }^{4}$, David O. Matson, ${ }^{4,5}$, Emmanuel Nzau6, Barthelemy Tandu ${ }^{6}$ \\ ${ }^{1}$ Christian Medical Institute of the Kasai, Tshikaji, Democratic Republic of the Congo (DRC) \\ ${ }^{2}$ School of Medicine, Kasayi University, Kananga, Democratic Republic of the Congo (DRC) \\ ${ }^{3}$ Biamba Marie Mutombo Hospital, Kinshasa, Democratic Republic of the Congo (DRC) \\ ${ }^{4}$ Graduate Program in Public Health, Eastern Medical School, Norfolk, USA \\ ${ }^{5}$ Department of Pediatrics, Eastern Virginia Medical School, Norfolk, USA \\ ${ }^{6}$ School of Medicine, University of Kinshasa, Kinshasa, Democratic Republic of the Congo (DRC) \\ Email: *leonmubi@yahoo.fr
}

How to cite this paper: Mubikayi, L., Chow, E.J., Matson, D.O., Nzau, E. and Tandu, B. (2016) A Case-Control Study of Obstetric Fistula Risk Factors in the Democratic Republic of the Congo. Open Journal of Obstetrics and Gynecology, 6, 740-753.

http://dx.doi.org/10.4236/ojog.2016.612092

Received: May 19, 2016

Accepted: November 18, 2016

Published: November 21, 2016

Copyright $\odot 2016$ by authors and Scientific Research Publishing Inc. This work is licensed under the Creative Commons Attribution International License (CC BY 4.0).

http://creativecommons.org/licenses/by/4.0/

\section{Abstract}

Background: Pregnant women in the Democratic Republic of Congo (DRC) are at increased risk for developing obstetric fistulas (OFs) as a result of obstructed labor, in conditions similar to many other African countries. No case-control study of biological and social risk factors for OF has been reported from the DRC. This study aimed to identify factors that would aid in prevention and early identification of women who are at risk of developing OF. Methods: Participants were enrolled in a case-control study at four obstetric clinics in the central DRC. Cases of OF were evaluated as they presented, then a control participant was enrolled among women presenting subsequently to the same clinic, seeking to match parity at the time of the fistula and tribe of the case. A questionnaire was administered to elicit physical, obstetric, demographic, socioeconomic, religion, geographic, and delivery attributes of the participants. Case-control comparisons sought to identify independent risk factors for OF in the total case-control pairs and in subgroups of the participants. Logistic regression was utilized to identify independent risk factors for OF in the total case-control study group and in selected subgroups of the participants, and linear regression was utilized to estimate the variation explained between case and control outcomes from the variables independently significant in the logistic regression models. Results: A total of 177 case-control pairs were enrolled. Among all pairs, shorter height of the case (odds ratio $=1.06,95 \%$ Confidence Limits $1.02-1.12$ ); more kilometers travelled to the delivery site $(1.02,1.01-1.02)$; her village, not town, residence $(\mathrm{OR}=5.52,2.72$ $11.2)$, and her lower professional status $(2.95,1.53$ - 5.72) were statistically independent factors associated with $\mathrm{OF}$ development. When applied in linear regression comparison of the pairs, these variables yielded an $r^{2}=0.48$, imputing $48 \%$ of the dif- 
ference in delivery outcome between the pairs was explained by these variables. Among the 38 pairs who were primigravida, the independent variables were more kilometers travelled to the delivery site $(1.02,1.00-1.05)$, village, not town, residence $(50.0,10.2$ 248.7), and facility intended for lower patient acuity (3.7 s, $\left.1.01-13.6, \mathrm{r}^{2}=0.66\right) \mathrm{pa}-$ tients who were matched on parity and tribe, the significant risk factors were professional status $(\mathrm{OR}=0.29)$, greater distance travelled to the clinic $(\mathrm{OR}=1.02,1.01$ 1.02), village, not town, residence $(5.52,2.72-11.2)$, and mother's lower professional status $(2.95,1.53$ - 5.72) when the OF occurred. Conclusions: Our study showed biological and social factors associated with the development of OF. Shorter height was the only biological risk factor found to be statistically significant in the study population. Other factors were related to limited resources and limited access to medical care.

\section{Keywords}

Obstetric Fistula, Case-Control, Risk Factors, Democratic Republic of the Congo

\section{Introduction}

Obstetric fistula (OF) is an acquired, abnormal communication between the vagina and one or more surrounding organs that is caused by an obstructed labor. Every year, 50,000 to 100,000 women are newly affected with OF, with an estimated count of more than 2 million women in Asia and sub-Saharan Africa living untreated with this diagnosis [1]. During delivery, compression of tissue during obstructed labor leads to compromised blood flow in the mother and subsequent necrosis of the devitalized tissue. Without a prompt response to lack of progress of labor, obstructed labor usually results in the death of the neonate. Obstructed labor is more likely when the size of the neonate's head is disproportionately large for the width birth canal. Fistulas between the vagina and bladder, vagina and rectum or among all three are most common; their variation complicates surgical approaches. Limited resources prevent women from seeking the help needed to prevent adverse delivery outcomes. Limited resources mean women do not receive the obstetrical care needed for a normal pregnancy and delivery. As many as 15 of 1000 pregnancies result in complications which includes obstetric fistulas [2]. When obstructed labor occurs, a skilled healthcare provider or access to C-section can provide the proper care to prevent fistula formation.

Cultural barriers prevent women from seeking help to correct their OF (3). Women with obstetric fistulas confront a misperception of being "unfit" for motherhood; a social stigma of uncleanliness, because of incontinence and smell of urine and/or feces; and, sometimes, ostracism by their husbands and families due to a belief that these women are cursed [3]. As a result, the women frequently are left to fend for themselves, including making a living and finding shelter in areas where these can be difficult to find, however, with proper treatment and education, these individuals can resume everyday life.

Three previous case-control studies of risk factors for OF have been published, each 
performed in Nigeria (Table 1). A woman's younger age at the time of marriage was a significant risk factor in each study, while the woman's shorter height was found to be a risk factor in two studies. Other risk factors of the woman and the father of the pregnancy found in these studies increased as the investigation of the studies became more comprehensive, expanding to include demographic, socioeconomic and/or geographic factors. The interaction of these factors was not assessed. Case-series studies have found one or more these factors, as well as others, to be common in women affected by OF, yet lack the inclusion of controls matched to the cases in these studies may indicate study-to-study differences are unrelated to risk of OF.

About 74 million persons live in the Democratic Republic of the Congo (DRC), of whom almost 20 million females are between the ages of 15 to 64 years [4]. The birth rate in 2012 was estimated to be 37.05 births per 1000 population [4] and women in the DRC bear an average of 6 children during their reproductive age [5]-[8]. Many Congolese women have developed $\mathrm{OF}$, most notoriously from rape fistula from continual violence in the East of the country, yet OF obstetric events is more common and of similar incidence across the country. We sought to identify risk factors for OF to prevent its occurrence in the DRC. The Democratic Republic of Congo is characterized by a very high maternal mortality rate is 549 deaths maternels/100,000 live births.

Most of these deaths are preventable and occur because of ignorance of the population, lack of road infrastructure, the lack of urgency and lack of qualified staff obstetric care. A woman with an obstetric emergency must be transported by bike and it can take hours before arriving at the hospital. A study of risk factors for OF development in the DRC was needed to provide epidemiological data to support efforts to prevent $\mathrm{OF}$ there.

\section{Methods}

\subsection{Study Design}

This was a retrospective, case-control study to discover biological and social factors that preceed occurrence of OF in multiple sites of the DRC.

Table 1. Previous case-control studies of obstetric fistulas.

\begin{tabular}{llll}
\hline \multicolumn{1}{c}{ Location } & $\begin{array}{c}\text { Year } \\
\text { published }\end{array}$ & $\begin{array}{c}\text { Number of Patients } \\
\text { Enrolled }\end{array}$ & \multicolumn{1}{c}{ Risk Factors Identified } \\
\hline $\begin{array}{l}\text { Maiduguri, } \\
\text { Northern Nigeria [4] }\end{array}$ & 1990 & $\begin{array}{l}241 \text { cases, } \\
148 \text { controls }\end{array}$ & $\begin{array}{l}\text { Younger age at marriage, shorter height } \\
\text { Northern Nigeria [6] }\end{array}$ \\
& 1999 & $\begin{array}{l}50 \text { cases, } \\
50 \text { controls }\end{array}$ & $\begin{array}{l}\text { Younger age at marriage, fewer parities, } \\
\text { husband lower status occupation, } \\
\text { husband fewer years of education }\end{array}$ \\
& & & $\begin{array}{l}\text { Younger age at marriage, shorter height, } \\
\text { illiteracy, lower social class, lack of }\end{array}$ \\
North-Eastern & 2007 & $\begin{array}{l}80 \text { cases, } \\
\text { Nigeria [7] controls }\end{array}$ & $\begin{array}{l}\text { employment, village rather than town } \\
\text { residence, further distance from health facility }\end{array}$
\end{tabular}




\subsection{Study Population}

Cases and controls were enrolled between July 2009 and July 2010 at obstetric clinics at four sites in central and southwest DRC: Lodja, Kabongo, Kole, and Kolwezi. Or surgeon evaluated women with OF for surgical repair and solicited their participation in the case-control comparison, for which they completed a questionnaire. Upon enrollment of a case, subsequent women being evaluated for obstetric and gynecological services at the same clinic were solicited for enrollment to be matched to a case based upon equal or closest parity at the parturition that was the parturition when OF developed in the case, as well as for being in the same tribe as the case. Cases lacking a found matched control were excluded. This study was approved by the institutional review boards at the DRC Ministry of Higher Education and University School of Public Health, and at Eastern Virginia Medical School.

The Christian Medical Institute of the Kasai (abbreviation "IMCK", in French) operates in the West Kasai and, in 2005, began distributing moringa trees to family compounds to reduce child malnutrition in its service area. We surveyed four villages of the Tshikaji health zone of West Kasai that were in various stages of moringa tree distribution, to assess whether a population-based effect upon the prevalence of pediatric malnutrition could be detected of moringa tree presence and/or utilization.

The Christian Medical Institute of the Kasai is a large multidisciplinary structure in the center of the Republic of Congo. It was built in 1954 by the American Presbyterian Mission in order to train young Congolese in nursing and laboratory.

The clinic at Tshikaji is located 16 kilometers south of Kananga, a city of more than one million inhabitants in West Kasai Provinces. The area served by the hospital of the Good Shepherd is inhabited by 165,000 people, but because of its good reputation, the hospital serves the majority of the population of the town of Kananga.

Kole and lodja are in eastern kasai province and Kolwezi, Kabongo: province of Katanga. Each site is the general hospital for reference. Kole hospital deserves 156,000 people, lodja: 280,000, Kabongo: 238,000 and Kolwezi for 350,000.

\subsection{Questionnaire Content and Administration}

The survey questionnaire was administered at the clinic site of enrollment by research coordinators and assessed both biological and social factors associated with OF development. Social and biological factors included in the study were determined to be statistically significant in previous studies $(3,4,5)$ or were hypothesized by the authors to be potential significant factors specific to the target population in the DRC.

Factors assessed because of their significant in previous studies included patient's age at marriage, height, patient's and infant's father's occupation and years of education, socioeconomic status, and, when the OF developed, patient's residence in a town or village and distance to the nearest healthcare facility. Other factors assessed in this study included number of previous pregnancies, number of abortions, number of living children, method of delivery, type of attendants at delivery, marital status at the time of OF development, and the woman's years of education. [check regression analyses for 
list of variables].

Socioeconomic status was measured indirectly by collecting information on the structural attributes of the home including the wall and roof. This measurement of socioeconomic status had previously been used successfully in a study conducted by the authors in the same region of the country [5] [8]. House materials showing an increase in socioeconomic status included mud, wood or fired brick and were recoded as 0,1 and 2, respectively. Roof material included either thatch or metal and were likewise recoded as 0 and 1 , respectively.

Profession for both the woman and her father were grouped as "none", "non-professional" or "professional" depending on the level of formal training required pursue that job. Individuals categorized as professional included teachers, nurses, doctors, and lawyers. Those who were small business owners were considered "non-professionals." Attendants at birth were similarly categorized as "professionals" and "non-professionals" but also included "friends/family." Those who were considered professionals included physicians, nurses and nurse midwives. Non-professionals included traditional birth attendants who have had no formal training.

Only factors referenced in the case-control studies found through the search and observational experience from working with the target population were included.

\subsection{Data Analysis}

Patients were stratified dichotomously based on the presence or absence of OF at the time of presentation to the clinic. Statistical analyses included a univariate analysis of the factors assessed in the questionnaire followed by a stepwise backwards-logistic regression to determine the odds ratios (confidence interval of 95\%). We used Epi Info 7 to do the analysis for our study.

We coded some variables for analysis, as follows: participant profession/occupation = 1 for accountant, chief of government sector, diamond mine manager, government inspector or agent, lawyer, minister/pastor, nurse, pharmacist, and teacher; $=2$ for blacksmith, carpenter, cook, diamond miner or seller, diver, chauffer, fisherman, fuel seller, hair stylist, domestic servant, hunter, industrial security guard, journalist, mechanic, policeman, Red Cross worker, repairman, secretary, small business owner, soldier, tailor, technician, telephone operator, salesman, and wood carver; and $=3$ for farm worker, student, and no profession. Wall structural materials were coded as follows: wall of brick $=1$, of mud $=2$, and of wood $=3$. Roof structural materials were coded as follows: roof of metal $=1$ and of thatch $=2$. A "Home Score" was generated from addition of these codes and could range from 2 to 5 . Birth attendant training was coded as follows: 1 = physician, midwive, or maternity clinic nurse, $2=$ traditional birth attendant, 3 = family or friend.

Physician, midwife or maternity nurse

$\begin{array}{ll}118(68 \%) & 156(88 \%) \\ 46(26 \%) & 19(11 \%) \\ 10(5.7 \%) & 2(1.1 \%) \\ 174(100 \%) & 177(100 \%)\end{array}$


Place of delivery

\section{Hospital}

Maternity or health center

Home

Total

$$
\begin{array}{ll}
66(38 \%) & 66(37 \%) \\
64(36 \%) & 71(40 \%) \\
46(26 \%) & 40(23 \%) \\
176(100 \%) & 177(100 \%)
\end{array}
$$

Duration (number of hours) of labor at the parity of the obstetric fistula was treated as a defining factor of "obstructed labor", which is the physiologic event that induces almost all obstetric fistulas in the settings of enrollment for this study in the Democratic Republic of the Congo. Therefore, duration of labor was excluded in the assessment of risk factors for obstetric fistula in the case-control comparisons.

Some variables in our survey instrument can be considered as either a risk factor for obstetric fistula or an outcome of having an obstetric fistula, or both. The woman's weight at enrollment was one factor we considered more likely to reflect the consequences of having an obstetric fistula than as a risk factor for its occurrence in our study. We believed it unlikely that we could accurately obtain even a reliable estimated pre-conceptional weight for either a case or a control, for the parity at which the obstetric fistula occurred. Other factors that could be more "outcome" than "risk" include... [gravida, para, and living children at enrollment...] We included such factors in the case-control comparisons, knowing that the interpretation of case-control differences would need to be cautious for "models" of risk that included those variables.

\section{Results}

\subsection{Participant Enrollment}

A total of 396 individuals were eligible for the study as a case or control (Figure 1). Of the 199 cases and 197 controls who completed the survey, 178 case-control pairs were

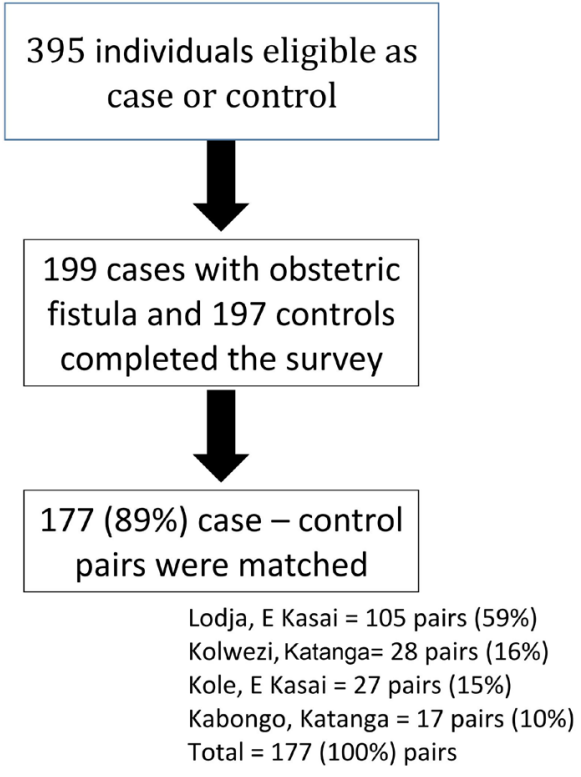

Figure 1. Enrollment of cases and controls. 
enrolled and matched based on parity at the time of the fistula. For 97 pairs in the Otetela tribe, cases and controls were matched on both parity and tribe to minimize unmeasured cultural factors. Our study looked at all 177 pairs matched on parity and separately also looked at the 97 pairs matched on parity and tribe, to see if differences occurred. Enrollment site (city, province).

\subsection{Population Demographic Data}

Table 2 includes the population demographic data of enrolled individuals. The mean age at marriage for cases was at 18 years, while controls were at 19 years. In general, cases presented to the clinic with a smaller body habitus including a shorter height and a lower weight than their matched controls. Women who had an OF also travelled a longer distance to arrive at the clinic and endured a longer labor process.

Table 2. Comparisons of 177 obstetric fistula case-controls pairs and of the fathers*.

\begin{tabular}{|c|c|c|}
\hline Attribute & Cases Mean, IQR (Range) & Controls Mean, IQR (Range) \\
\hline \multicolumn{3}{|l|}{ Demographic Attributes } \\
\hline Woman's marriage age (yrs)+ & $18,16-19(12-25)$ & $19,18-20(12-26)$ \\
\hline \multicolumn{3}{|l|}{0.003} \\
\hline Woman's age at parity of OF (yrs)+ & $22,18-26(8-43)$ & $23,19-41(16-41)$ \\
\hline \multicolumn{3}{|l|}{0.20} \\
\hline Father's marriage age (yrs)+ & $26,22-29(17-52)$ & $26,22-28(15-49)$ \\
\hline \multicolumn{3}{|l|}{0.76} \\
\hline Father's age at parity of OF (yrs)+ & $31,26-38(18-66)$ & $30,26-36(16-56)$ \\
\hline \multicolumn{3}{|l|}{0.17} \\
\hline Yrs father older at marriage+ & $9,4-10(-2-36)$ & $7,4-9(-5-33)$ \\
\hline \multicolumn{3}{|l|}{0.032} \\
\hline \multicolumn{3}{|c|}{ Marriage status at parity of OF: Number (\%) } \\
\hline Single & $20(11 \%)$ & $13(7.3 \%)$ \\
\hline Divorced & $2(1.1 \%)$ & $2(1.1 \%)$ \\
\hline Estranged & $5(3.1 \%)$ & $3(1.7 \%)$ \\
\hline Widowed & $1(0.6 \%)$ & $0(0 \%)$ \\
\hline Married & $147(84 \%)$ & $159(90 \%)$ \\
\hline Total & $175(100 \%)$ & $177(100 \%)$ \\
\hline \multicolumn{2}{|c|}{ Woman's level of education at enrollment: Number (\%) } & $116(66 \%)$ \\
\hline None & $68(39 \%)$ & $21(12 \%)$ \\
\hline Primary & $77(44 \%)$ & $36(21 \%)$ \\
\hline Secondary & $30(17 \%)$ & \\
\hline University & $0(0 \%)$ & $2(1.1 \%)$ \\
\hline Total & $175(100 \%)$ & $175(100 \%)$ \\
\hline
\end{tabular}




\section{Continued}

\begin{tabular}{|c|c|c|}
\hline \multicolumn{3}{|c|}{ Woman's profession at enrollment: Number (\%) } \\
\hline Level 0 & $1(0.6 \%)$ & $19(11 \%)$ \\
\hline Level 1 & $13(7.4 \%)$ & $84(48 \%)$ \\
\hline Level 2 & $160(92 \%)$ & $72(41 \%)$ \\
\hline Total & $174(100 \%)$ & $175(100 \%)$ \\
\hline \multicolumn{3}{|c|}{ Father's level of education at enrollment: Number (\%) } \\
\hline University & $2(1.2 \%)$ & $24(14 \%)$ \\
\hline Secondary & $106(64 \%)$ & $135(77 \%)$ \\
\hline Primary & $35(21 \%)$ & $14(8.0 \%)$ \\
\hline None & $23(14 \%)$ & $3(1.7 \%)$ \\
\hline Total & $166(100 \%)$ & $176(100 \%)$ \\
\hline \multicolumn{3}{|c|}{ Father's profession at enrollment: Number (\%) } \\
\hline Level 0 & $14(8.5 \%)$ & $38(22 \%)$ \\
\hline Level 1 & $60(37 \%)$ & $92(54 \%)$ \\
\hline Level 2 & $90(55 \%)$ & $42(24 \%)$ \\
\hline Total & $169(100 \%)$ & $168(100 \%)$ \\
\hline \multicolumn{3}{|c|}{ Religion match of woman and father: Number (\%) } \\
\hline Yes $(\#, \%)$ & $106(65 \%)$ & $151(88 \%)$ \\
\hline No $(\#, \%)$ & $58(35 \%)$ & $21(12 \%)$ \\
\hline Total & $164(100 \%)$ & $172(100 \%)$ \\
\hline \multicolumn{3}{|c|}{ Religion match of case and control: Number (\%) } \\
\hline Yes $(\#, \%)$ & $37(21 \%)$ & $37(21 \%)$ \\
\hline No $(\#, \%)$ & $136(79 \%)$ & $136(79 \%)$ \\
\hline Total & $173(100 \%)$ & $173(100 \%)$ \\
\hline \multicolumn{3}{|c|}{ Structural attributes of residence: Number (\%) } \\
\hline \multicolumn{3}{|l|}{ Wall } \\
\hline Wood (\#, \%) & $90(51 \%)$ & $42(24 \%)$ \\
\hline Mud (\#, \%) & $79(45 \%)$ & $107(60 \%)$ \\
\hline Fired brick (\#, \%) & $8(4.5 \%)$ & $28(16 \%)$ \\
\hline Total & $177(100 \%)$ & $177(100 \%)<0.001$ \\
\hline \multicolumn{3}{|l|}{ Roof } \\
\hline Thatch (\#, \%) & $160(90 \%)$ & $124(70 \%)$ \\
\hline Metal (\#, \%) & $17(10 \%)$ & $52(30 \%)$ \\
\hline Total (\#, \%) & $177(100 \%)$ & $176(100 \%)<0.001$ \\
\hline
\end{tabular}




\section{Continued}

Home score\#

$2(\#, \%)$

$89(50 \%)$

$27(15 \%)$

$3(\#, \%)$

$72(41 \%)$

$20(11 \%)$

$4(\#, \%)$

$8(4.5 \%)$

$92(52 \%)$

$5(\#, \%)$

$8(4.5 \%)$

37 (21\%)

Total (\%)

$177(100 \%)$

$176(100 \%)$

Residence setting at parity of $\mathrm{OF}$

Village (\#, \%)

$144(82 \%)$

$46(26 \%)$

Town (\#, \%)

$32(18 \%)$

$129(74 \%)$

Total

$176(100 \%)$

$175(100 \%)$

Distance $(\mathrm{Km})$ to delivery site

1

$3(1.8 \%)$

$58(34 \%)$

$1-2$

$13(7.80)$

89 (52)

$1-5$

$30(18.0)$

$129(75)$

$1-143$

$137(82)$

166 (97)

$1-149$

149 (89)

167 (98)

$\geq 150$

18 (11)

$4(2.3)$

Physical and Obstetric attributes

Height $(\mathrm{cm})+$

Weight $(\mathrm{Kg})+$

Gravida at enrollment+

Para at enrollment +

Living children at enrollment +

Duration of labor at parity of OF (hrs)+

Route of delivery with parity of OF: Number (\%)

Vaginal

Caesarean

Total

Highest training level of birth attendant: Number (\%)

Family and/or friend

Traditional birth attendant

Physician, midwife or maternity nurse

Total

Place of delivery: Number (\%)

Hospital

Maternity or health center

Home

Total

$$
\begin{gathered}
151,136-155(134-171) \\
48,42-52(29-69) \\
3,2-6(1-15) \\
2,1-6(1,15) \\
0,0-2,(0-9)
\end{gathered}
$$

$82,60-108(24,576)$

$$
\begin{gathered}
129(73 \%) \\
47(27 \%) \\
176(100 \%)
\end{gathered}
$$

$$
10(5.7 \%)
$$$$
46(26 \%)
$$$$
118(68 \%)
$$$$
174(100 \%)
$$

$64(36 \%)$

$46(26 \%)$

$176(100 \%)$
$155,151-158(134-169)$

$56,50-61(42-86)$

4, 4 - 6, (1 - 16)

$4,2-6(1-15)$

$2,2-4(0,14)$

12,7 - $24(0$ - 96)

145 (84\%)

27 (16\%)

$172(100 \%)$

$2(1.1 \%)$

19 (11\%)

$156(88 \%)$

177 (100\%)

66 (37\%)

$71(40 \%)$

40 (23\%)

177 (100\%)

*Abbreviations: "OF" = obstetric fistula, "yrs" = years, "OR" = odds ratio, "hrs" = hours; "+" Numbers in parentheses indicate "Median, 25\% - 75\% Quartiles (Range)”; \# See Methods for definition of Level or Score. 


\subsection{Univariate Analysis of Variables (Table 3)}

While $63.7 \%$ of controls were older than 18 years, only $54.7 \%$ of cases were included in this age range at marriage. The other half of the cases was younger than 18 including $5.9 \%$ who were $<15$ years old at marriage. Comparatively only $2.3 \%$ of controls were $<15$ years old at marriage. With regards to marital status, most cases (84.1\%) identified as being married at the time that the fistula occurred. However, at the time of presentation to the clinic for fistula repair, only $53.9 \%$ of cases were married. On the other hand, $90.4 \%$ of controls were married at the same parity at which cases developed a fistula and this increased to $93.8 \%$ at the time of presentation to the clinic. Fathers of women with fistulas tended to be older than their control counterparts with $24 \%$ at age 30 and older compared to $16.9 \%$, respectively. Most cases lived in housing using cheaper materials than controls. Over $50 \%$ of cases lived in housing that had mud walls while $<10 \%$ had metal roofs. About $75 \%$ of controls lived in wood or fired brick buildings with $29.4 \%$ with metal roofs. Women who developed fistulas also tended to live in villages at the time of their fistula as opposed to $75 \%$ of controls who lived in the city

Table 3. Independent factors that occurred more frequently in all cases and in subgroups with obstetric fistula than in controls, by differing parity match within the case-control pair.

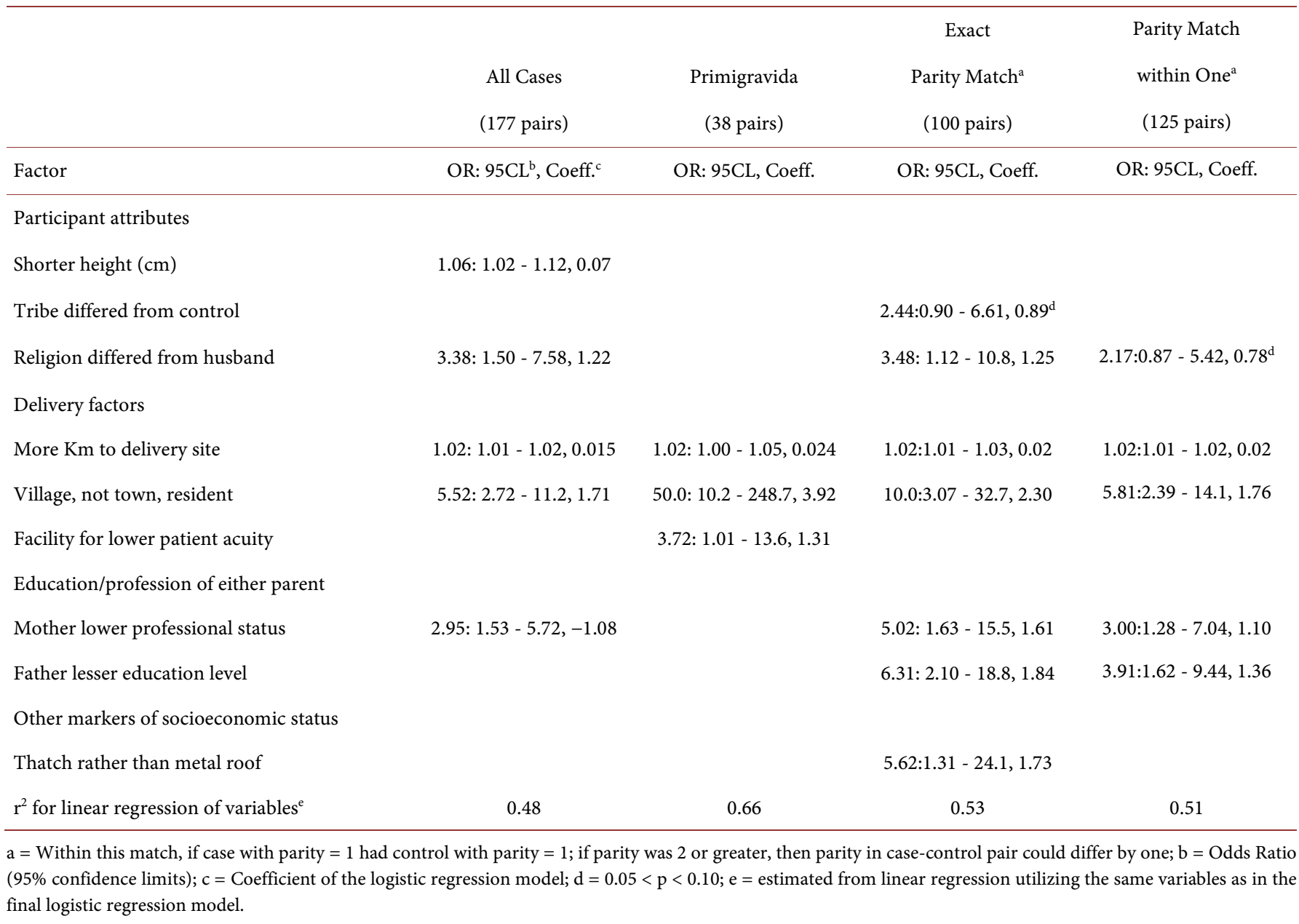


during that same point in their parity. When assessing distance needed to travel to the health clinic, $72 \%$ of controls traveled $<5 \mathrm{~km}$ and $80.7 \%$ of cases traveled $>10 \mathrm{~km}$. There were also educational differences between cases and controls in both the women and their fathers. About $83 \%$ of cases' highest level of education was primary or they had no formal education at all. This is in contrast to controls where $67 \%$ have either had secondary or university education. Interestingly, $14 \%$ of fathers of controls compared to $1.2 \%$ of fathers of cases had a university education. For families dealing with an obstetric fistula, $92 \%$ of cases identified as having no profession as well as $58 \%$ of their fathers. Approximately $60 \%$ of women without fistulas were small business owners or had a professional occupation. Fathers of the controls had a similar breakdown with $73.8 \%$ either identified as having jobs as small business owners or jobs that required professional training. During delivery, cases had fewer professionals present at $68 \%$ compared to controls at $87.1 \%$ as well as increased hours of labor including no cases with labor lasting less than 10 hours. Lastly, patients with no history of a fistula were more likely to have the same religion as their spouse at $87.4 \%$. Only $64.8 \%$ of cases shared the same religion as their father.

\subsection{Independent Factors Associated with the Risk of OF Development (Table 4)}

OF the biological factors assessed in the study, only a shorter height was found to be a significant risk factor (0.87) among those matched only on parity at the time of the fistula which is consistent with previous studies. No other biological risk factors were found to be a factor in the development of obstetric fistula and none were found in those patients matched on parity and tribe. Among those matched on parity only, living in the village versus the town, increased distance needed to travel to the health clinic, and decreasing wall score were associated with an increase risk for developing an OF. These three factors were also found to be significant in pairs matched on both parity and tribe. Additionally, a decrease in the patient's professional status and couples who do not share the same religion have an increase risk of developing an OF in the woman.

Odds ratios are listed in two separate groups. The first group includes all matched cases and controls by parity at the time of the fistula (Four Towns) in the study. The second column shows the group of cases who were matched to controls based on parity at the time of the fistula as well as the tribe Otetela. Numbers in parentheses indicate the $95 \%$ confidence intervals. Professional status was converted to a "score" to be included in the odds ratio calculation where $0=$ no job, 1 = non-professional occupation, and 2 = professional occupation. Wall material was similarly converted to a "score" with $0=$ mud, $1=$ wood, and $2=$ fired brick. Highest training level of birth attendant.

As cases of obstetric fistula presented for clinical evaluation, they were consented for participation in this survey. Once a case was enrolled, subsequent patients visiting the same obstetric clinic were screened for willing control participants, enrolling those whose parity was the same as (for primigravida) or as close as possible to (secundi-gravida and higher) that of an enrolled case. 
Table 4. Independent factors more likely to occur in cases of obstetric fistula than in controls, by matching of tribe or religion within the case-control pair.

\begin{tabular}{|c|c|c|c|}
\hline \multirow[b]{3}{*}{ Factor } & \multirow{3}{*}{$\begin{array}{c}\text { Otetela Tribe } \\
\text { (97 pairs) } \\
\text { OR: } 95 \mathrm{CL}^{\mathrm{a}} \text {, Coeff. }{ }^{\mathrm{b}}\end{array}$} & \multirow{2}{*}{$\begin{array}{l}\text { Luba Tribe } \\
\text { (18 pairs) }\end{array}$} & \multirow{3}{*}{$\begin{array}{l}\text { Same Religion } \\
\text { (37 pairs) } \\
\text { OR: 95CL, Coeff. }\end{array}$} \\
\hline & & & \\
\hline & & OR: 95CL, Coeff. & \\
\hline \multicolumn{4}{|l|}{ Participant attributes } \\
\hline Shorter height & & $1.26: 1.07-1.47,0.23$ & \\
\hline \multicolumn{4}{|l|}{ Delivery factors } \\
\hline More $\mathrm{Km}$ to delivery site & $1.04: 1.02-1.07,0.04$ & & $1.02: 1.00-1.04,0.02$ \\
\hline Less training of attendant(s) & $3.32: 1.08-10.2,1.20$ & & \\
\hline \multicolumn{4}{|l|}{ Education/profession of either parent } \\
\hline Mother lesser professional status & $5.80: 2.16-15.6,1.76$ & & $18.9: 2.22-160.0,2.94$ \\
\hline Father lesser education level & $3.97: 1.65-9.56,1.38$ & & \\
\hline \multicolumn{4}{|c|}{ Other markers of socioeconomic status } \\
\hline Wall material & $12.3: 3.90-38.6,2.51$ & & \\
\hline $\mathrm{r}^{2}$ for linear regression of factors ${ }^{\mathrm{c}}$ & 0.60 & 0.29 & 0.41 \\
\hline
\end{tabular}

\section{Discussion}

Our study is the $4^{\text {th }}$ case-control study identifying factors associated with obstetric fistula development and is the first to take place in the DRC. The results of the data collected included biological and social factors. While the univariate analysis showed some differences in many of the biological and social risk factors among cases and controls, not all were determined to be significant when calculating the stepwise logistic regression. The only biological risk factor found in our study was a shorter height which is consistent with previous studies in Nigeria (Table 1). All other risk factors including those for cases matched with controls on parity and tribe were considered to be social factors that have an indirect impact on the development of fistulas. A lower professional status, increased distance to the health clinic, and residence in a village rather than a town were found to increase the chance of developing an OF and were also found to be significant in other studies. Significant risk factors found to be novel to our particular study included a lower wall score (a surrogate for socioeconomic status) and couples who did not share the same religion.

There are many factors that may contribute to the development of obstetric fistulas. 
It is commonly believed that individuals who are younger with a smaller body habitus including shorter height and lower weight are more at risk for developing an OF. The reason is that although these women are capable of conception, their bodies have not matured sufficiently to allow an uncomplicated passage of the baby through the birth canal. This is further complicated by situations where families are far from trained professionals who would be able to provide emergency Caesarean sections to prevent compromise of the baby and the surrounding tissue. As seen from our data, those who had to travel further to the health clinic and those who lived in a village rather than a town at the time of the fistula were more likely to develop an OF. Lack of resources or knowledge of the signs and symptoms of an obstetric emergency may also play a role in fistula development. Again, the results of our study showed that those with a lower socioeconomic status or a lower professional status had less access to adequate medical knowledge and care and were put at increased risk for obstetric problems including fistula development.

From the data collected in our study also we were able to identify two additional factors that have not been documented in previous studies as factors associated with OF. One of these was socioeconomic status. In the DRC, social norms prevent directly asking individuals salary or social class, thus an indirect assessment of resources by assessing materials used to build the family's home was used. This system had been used previously in a household survey study that we had conducted in the DRC that correlated with socioeconomic status of the family. Socioeconomic status is important to indicate the types of resources that the family has access to and the type of care that they are able to afford when problems arise during labor and delivery. Secondly, we also found that couples who share a religion are associated with a decreased chance of developing an $\mathrm{OF}$ in the woman. The reasons for this may be due to a more cohesive nature of family dynamics, collective decision-making, and channeled resources in families with a single religion. This would allow families to make decisions about obstetric emergencies more quickly and more efficiently than those in which differing opinions exist.

Our study also had limitations. Due to the inherent nature of a retrospective study, there is recall bias that may limit the accuracy of data with regards to factors that took place at the time of the fistula development. Additionally, the ability to recall biological factors including height and weight at the time of the fistula development also limited assessment of factors. Not all questions were completed in each survey which limited our ability to compare all cases and controls by each factor. As this was a case-control study, only associations could be made from the analysis of the data and no cause and effect could be firmly established.

Despite the limitations of our study, this is the largest case-control study to look at factors associated with OF development and the only study taking place in the DRC. These findings can help target and identify women who are at increase risk for developing an OF and educate them about the risks of becoming pregnant before their bodies have matured and to recognize the signs and symptoms associated with obstructed labor and emergency delivery. Furthermore, the identification of at risk individuals 
may also help identify those who have developed OF and help them seek care more quickly to reduce morbidity in the population. Resources aimed at helping child-bearing women can also be oriented to reduce risk factors in target populations and increase protective factors to lower OF rates. We hope that the findings of this study will bring much needed attention to this serious condition and provide information to help those who are most likely to develop an OF.

\section{References}

[1] (2010) WHO: 10 Facts on Obstetric Fistula. World Health Organization.

[2] Glauser, W. (2008) Finding a Balance in the Treatment and Prevention of Obstetric Fistula. CMAJ, 178, 1527-1529. http://dx.doi.org/10.1503/cmaj.080693

[3] (2012) CIA World Factbook: Democratic Republic of the Congo. US Central Intelligence Agency.

[4] Ampofo, E.K., Omotara, B.A., Out, T. and Uchebo, G. (1990) Risk Factors of Vesico-Vaginal Fistulae in Maiduguri, Nigeria: A Case-Control Study. Tropical Doctor, 20, 138-139.

[5] http://www.unfpa.org/sowmy/resources/docs/country_info/profile/en_DRC_SoWMy_Profi le.pdf

[6] Ojanuga Onolemhemhen, D. and Ekwempu, C.C. (1999) An Investigation of Sociomedical Risk Factors Associated with Vaginal Fistula in Northern Nigeria. Women Health, 28, 103 116. http://dx.doi.org/10.1300/J013v28n03_07

[7] Melah, G.S., Massa, A.A., Yahaya, U.R., Bukar, M., Kizaya, D.D. and El-Nafaty, A.U. (2007) Risk Factors for Obstetric Fistulae in North-Eastern Nigeria. Journal of Obstetrics and $G y$ naecology, 27, 819-823. http://dx.doi.org/10.1080/01443610701709825

[8] Onsrud, M., Sjøveian, S., Luhiriri, R. and Mukwege, D. (2008) Sexual Violence-Related Fistulas in the Democratic Republic of Congo. International Journal of Gynecology \& Obstetrics, 103, 265-269. http://dx.doi.org/10.1016/j.ijgo.2008.07.018

Submit or recommend next manuscript to SCIRP and we will provide best service for you:

Accepting pre-submission inquiries through Email, Facebook, LinkedIn, Twitter, etc. A wide selection of journals (inclusive of 9 subjects, more than 200 journals)

Providing 24-hour high-quality service

User-friendly online submission system

Fair and swift peer-review system

Efficient typesetting and proofreading procedure

Display of the result of downloads and visits, as well as the number of cited articles

Maximum dissemination of your research work

Submit your manuscript at: http://papersubmission.scirp.org/

Or contact ojog@scirp.org 